
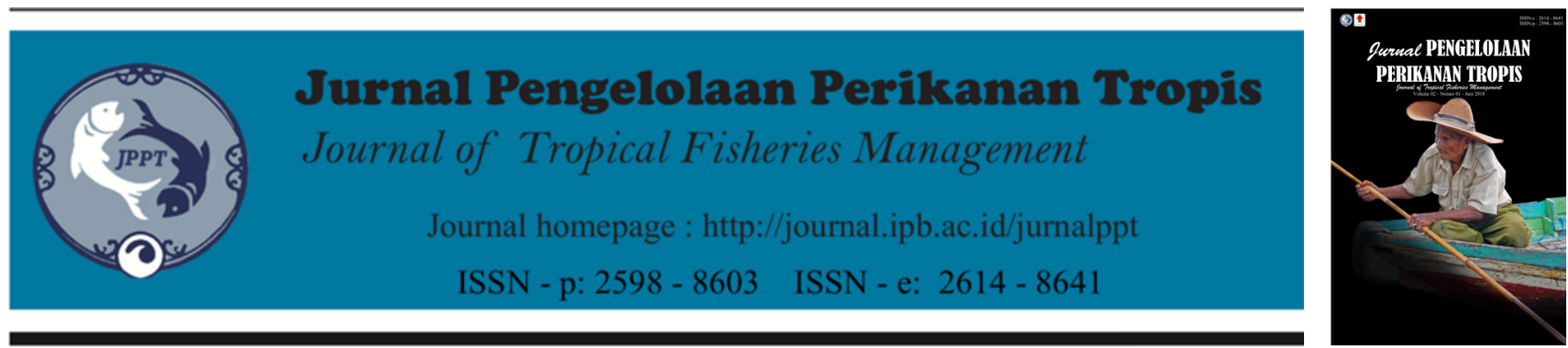

\title{
Kerentanan Perikanan Bycatcth Tuna dari Samudera Hindia: Evidance dari Pelabuhan Perikanan Pelabuhanratu
}

\author{
Vulnerability of Bycatch Tuna Fisheries from Hindian Ocean: Evidance from Pelabuhanratu Landing Port
}

\author{
Yonvitner $^{1)}$, Masykur Tamanyira ${ }^{2)}$, Wawan Ridwan ${ }^{2)}$, A Habibi $^{2)}$, Destilawati ${ }^{3)}$, \\ Surya Gentha Akmal ${ }^{4}$
}

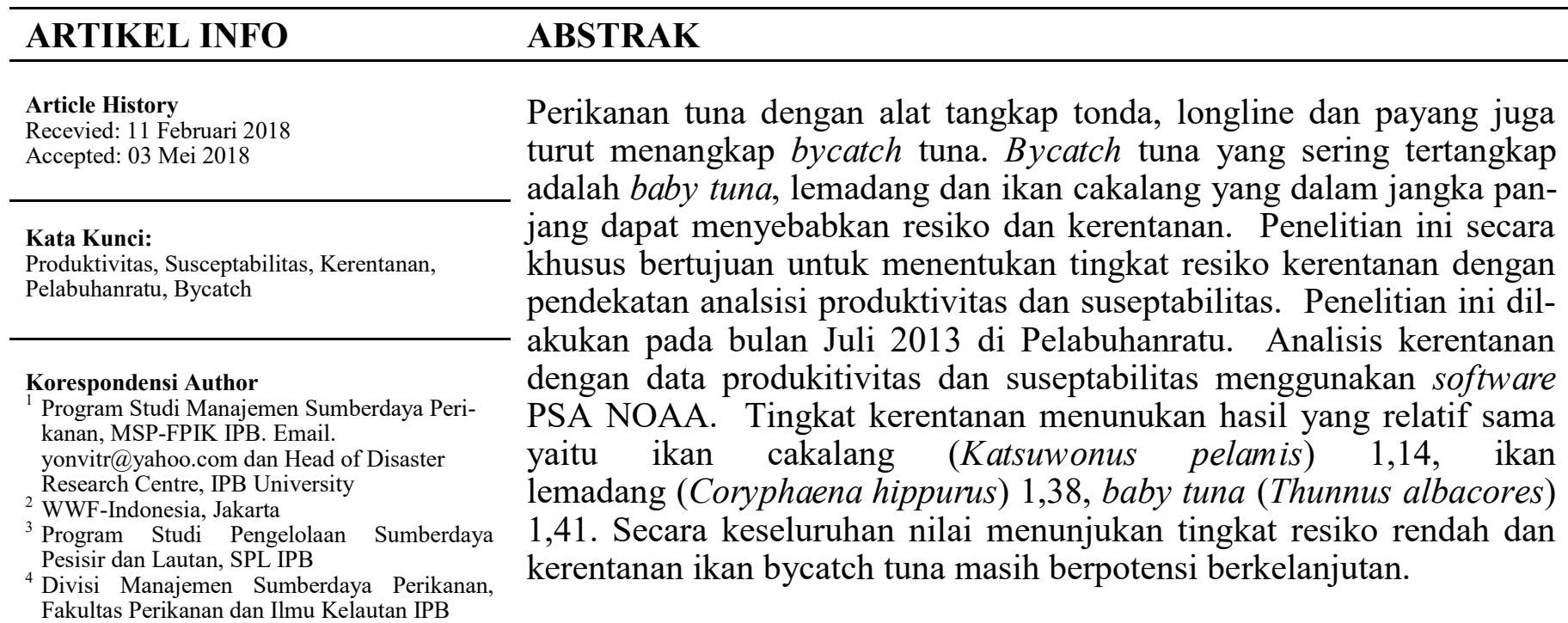

\section{PENDAHULUAN}

Ikan bycatch tuna merupakan kelompok ikan yang bermigrasi mengikuti scholling tuna. Produksi ikan tuna bersumber dari Samudera Pasifik 68\% dan Samudera Hindia sekitar 22\% dan sisanya $10 \%$ dari Samudera Atlantik dan Laut Mediterania. Komposisi perikanan tuna yang tertangkap meliputi Cakalang (Skipjack Tuna) 60\%, Madidihang (Y ellow fin tuna) $24 \%$, big eye $10 \%$, dan Albacore 5\%, sisanya tuna sirip biru sekitar $1 \%$ bahkan Sunoko and Hwang (2014) mencatat komposisi skipjack 7,27\%, baby tongkol 8,09\%. Dalam perikanan tuna bycatch seringkali lebih tinggi komposisinya yang dapat menyebabkan tingginya resiko kerentanan bahkan kepunahan stok.

Kerentanan juga disebabkan penggunaan alat tangkap jaring (purse seine) selain pancing (hook and line). Penggunaan alat tangkap baru tersebut memicu tingkat eksploitasi yang tinggi yang akhirnya menyebabkan penurunan stok. Penangkapan bycatch yang hampir $60 \%$ dalam perikanan tuna sudah full exploitation dan beresiko rentan (Sunoko and Hwang, 2014).

Effort penangkapan yang tinggi mempercepat meningkatnya keterancaman perikanan tuna termasuk baycatch. Agar kerentanan tidak mengarah pada pengurasan dan stok menjadi turun dari bycatch makan diperlukan upaya mitigasi. Untuk itu status kerentanan perikanan tuna harus dievaluasi agar dapat dibuat kebijakan pengelolaan yang terukur.

Keterancaman dapat dievaluasi dari parameter produktivitas dan suceptabilitas. Produktivitas menunjukan kemampuan untuk pulih secara cepat ketika stoknya berkurang, sementara keterancaman (susceptibility) adalah potensi dipengaruhinya stok oleh adanya aktivitas penangkapan. Kajian kerentanan bukan hal yang baru dilakukan, karena merupakan pendekatan yang umum dalam menilai resiko penangkapan terhadap perikanan. Beberapa kajian yang sudah diujikan pada beberapa jenis seperti pada ikan sidat tropical eel (Yonvitner, 2017), ikan pelagis kecil (Puspita et al, 2017) dan revisi dari reference point untuk ikan pelagis kecil untuk wilayah 
tropis (Yonvitner, 2017). Karena praktek perikanan tuna, bycatch yang selalu ditangkap, dikhawatirkan akan terganggu keberlanjutanya. Penelitian ini bertujuan mengkaji tingkat kerentanan perikanan baycatch tuna, serta memberikan rekomendasi pengelolaan dalam jangka panjang.

\section{METODOLOGI}

\section{Lokasi Penelitian}

Kegiatan penelitian dilaksanakan selama Juli 2013 di PPP Pelabuhanratu. Data ikan tuna dan bycatch diperoleh dari nelayan yang menangkap di perairan Selatan Jawa Samudera Hindia (WPP 573). Daerah penangkapan nelayan tuna Pelabuhanratu sebagian besar diselatan Jawa seperti disajikan pada Gambar 1 berikut.

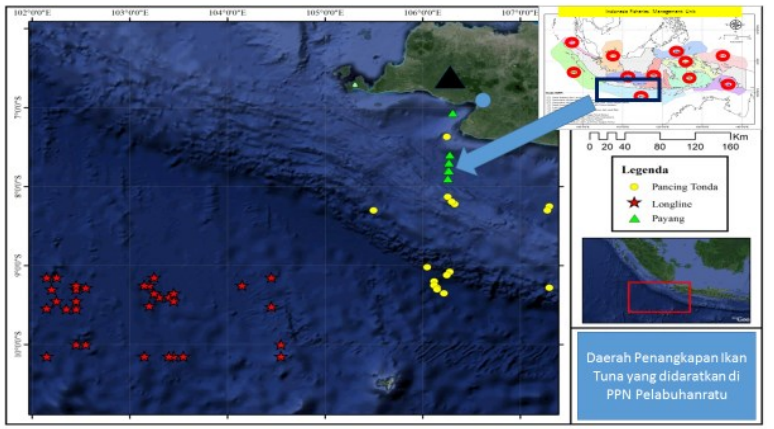

Gambar 1. Lokasi Penangkapan Tuna di Selatan Pelabuhanratu

Data produksi, upaya tangkap, kondisi social ekonomi,fishing ground, ekosistem diperoleh dari catatan pengumpul tuna, eksportir, riset lainya, dan sumber wawancara. Ikan tangkapan samping perikanan tuna diidentifikasi dengan cepat (rapid assessment), kemudian dilakukan pengambilan contoh secara acak untuk masingmasing spesies berdasarkan ukuran ikan, jumlah ikan yang mewakili. Kemudian masing-masing jenis ikan diukur panjang dan bobot, kemudian di bedah untuk analisis fekunditas dan makanan. Pengamatan sampel dilakukan pada Laboratorium biologi perikanan IPB.

\section{Parameter dan Analisis}

Parameter kerentanan menggunakan pendekatan multikriteria secara kualitatif dari dua atribut utama yaitu produktivitas dan suceptabilitas. Atribut produktivitas memiliki 10 parameter dan atribut suceptabilitas 12 parameter. Analisis indek kerentanan menggunakan analisis indek jarak (Euclidean Distance) (Patrick, 2009). Parameter yang dikumpulkan datanya ditampilkan pada Tabel 1. Penentuan indek kerentanan dari parameter produktivitas dan susceptibilitas (keterancaman) menggunakan pendekatan skoring.

Setiap parameter memiliki skor bobot parameter, skor atribut, dan skor kualitas data. Skor dari bobot berkisar antara $0-4$ dimana $(0=$ tidak penting; $1=$ kurang penting; $2=$ penting; $3=$ lebih penting; $4=$ sangat penting. Skor atribut produktivitas antara 1-3 dimana ( $1=$ rendah; $2=$ medium; $3=$ tinggi) dan skor susceptabilitas juga dalam skala 1-3 dimana skor (1=rendah; 2=sedang; dan 3 tinggi). Skor kualitas data antara 1-5 dimana skor $(1=$ data banyak dan lengkap; $2=$ data terbatas (temporal/ spasial); $3=$ data menggunakan pendekatan pada genus atau family; $4=$ data tersedia pada informasi yang belum dipublish seperti di web/blog/paper dan materi presentasi dan $5=$ tidak ada data yang menjelaskan. Skor atribut dari setiap spesies kemudian dapat ditampilkan dalam plot scater $\mathrm{x}$ y. Secara keseluruhan rata-rata produktivitas tergolong tinggi apabila rata-rata skor besar atau sama dengan 3, dan rendah sama dengan 1. Susceptabilitas tergolong rendah bila mendekati skor 1 dan tinggi mendekati atau sama dengan 3 .

Tabel 1 Parameter Produktivitas dan Suceptabilitas

\begin{tabular}{|c|c|c|c|}
\hline Parameter Produktivitas & Jenis Data & Analysis & Pengumpulan data \\
\hline $\begin{array}{l}\text { Pertumbuhan Instrisik (Intrinsic } \\
\text { growth) }\end{array}$ & Produksi dan Upaya & Growth Analysis & In-situ \\
\hline Umur Maksimum (Max age) & Panjang & Length frequency analysis & In-situ \\
\hline Ukuran Maksimum (Max size) & Panjang & Length frequency analysis & In-situ \\
\hline $\begin{array}{l}\text { Lanju pertumbuhan } / \mathrm{K} \text { (Growth coeffi- } \\
\text { cient) }\end{array}$ & Panjang & Bartalannfy & In-situ \\
\hline Kematian alami/M (Natural mortality) & Panjang & Persamaan empiric Pauly & In-situ \\
\hline Fekunditas (Fecundity) & Telur ikan & Gravimetrik dan volumetric & In-situ and Ex-situ \\
\hline $\begin{array}{l}\text { Strategy pemijahan (Breeding strate- } \\
\text { gy) }\end{array}$ & Diameter telur & Cohort analysis & In-situ and Ex-situ \\
\hline Pola recruitment (Rekruitmet pattern) & Length frekuensi & $\begin{array}{l}\text { Normsep and Gausian distri- } \\
\text { bution }\end{array}$ & In-situ \\
\hline $\begin{array}{l}\text { Umur saat matang gonad (Age at Ma- } \\
\text { turity) }\end{array}$ & $\begin{array}{l}\text { Length dan Diameter } \\
\text { telur }\end{array}$ & Length frequency analysis & In-situ \\
\hline $\begin{array}{l}\text { Rata-rata tropic level (Mean tropic } \\
\text { level) }\end{array}$ & Makanan & Niche overlap & In-situ \\
\hline
\end{tabular}




\begin{tabular}{|c|c|c|c|}
\hline Parameter Seceptability & Jenis Data & Analysis & Pengumpulan data \\
\hline Tumpang tindih area (A rea overlap) & Distribusi & Distribusi & $\begin{array}{l}\text { In-situ/ } \\
\text { Quisioner }\end{array}$ \\
\hline $\begin{array}{l}\text { Daerah Sebaran geografis (Concentrasi } \\
\text { geografis) }\end{array}$ & Distribusi & Distribusi & $\begin{array}{l}\text { In-situ/ } \\
\text { Quisioner }\end{array}$ \\
\hline $\begin{array}{l}\text { Tumpang tindih vertical (Vertical } \\
\text { overlap) }\end{array}$ & Distribusi & Dsitribusi & $\begin{array}{l}\text { In-situ/ } \\
\text { Quisioner }\end{array}$ \\
\hline $\begin{array}{l}\text { Rasio Mortalitas fishing terhadap ala- } \\
\text { mi (F / M ) }\end{array}$ & Length Data & Persamaan Pauly dan Evanof & In-situ \\
\hline $\begin{array}{l}\text { Biomass stok pemijahan SSB } \\
\text { (spawning stock biomass) }\end{array}$ & $\begin{array}{l}\text { Biomass Hasil tangka- } \\
\text { pan }\end{array}$ & Ricker & In-situ \\
\hline Migrasi musiman (Seasonal migration) & Data Migrasi & Pola Distribusi & $\begin{array}{l}\text { In-situ/ } \\
\text { Quisioner }\end{array}$ \\
\hline $\begin{array}{l}\text { Kelompok Berkumpul (Schooling ag- } \\
\text { gregation) }\end{array}$ & Schooling & Pola Distribusi & $\begin{array}{l}\text { In-situ/ } \\
\text { Quisioner }\end{array}$ \\
\hline $\begin{array}{l}\text { Efek morphologi (Morfology affect- } \\
\text { ing) }\end{array}$ & Morfology & Morfologis & $\begin{array}{l}\text { In-situ/ } \\
\text { Quisioner }\end{array}$ \\
\hline $\begin{array}{l}\text { Kemampuan hidup setelah penangka- } \\
\text { pan (Survival after Capture) }\end{array}$ & Morfology & Morfologis & $\begin{array}{l}\text { In-situ/ } \\
\text { Quisioner }\end{array}$ \\
\hline $\begin{array}{l}\text { Nilai ekonomi ikan (Desirability/Value } \\
\text { of the fishery) }\end{array}$ & Nilai ekonomi ikan & Nilai produksi & $\begin{array}{l}\text { In-situ/ } \\
\text { Quisioner }\end{array}$ \\
\hline $\begin{array}{l}\text { Dampak perikanan pada ekosistem } \\
\text { (Fishery Impact to essential fish habi- } \\
\text { tat) }\end{array}$ & Kulitas Habitat & Distribusi dan habitat & $\begin{array}{l}\text { In-situ/ } \\
\text { Quisioner }\end{array}$ \\
\hline
\end{tabular}

Sumber: Patrick et al, 2009

Skor kerentanan secara keseluruhan (v) dari stok di hitung menggunakan persamaan jarak Euclidean dengan formulasi sebagai berikut (Patrick, 2009):

$$
V=\sqrt{(p-3)^{2}+(s-1)^{2}}
$$

Dimana; $\mathrm{V}=$ Indek kerentanan

$\mathrm{P}=$ Skor indek produktivitas

$\mathrm{S}=$ Skor indek suceptabilitas

Reference point nilai hasil analisis kerentanan (vulnerability) yaitu nilai skor 1,8 . Apabila skor kerentanan besar $(>1,8)$, maka dapat diasosiasikan stok mengalami tekanan dan kerentanan yang tinggi atau potensial terjadi overfishing. Apabilai nilai skor kecil dari $(<1,8)$ bisa terjadi karena productivity tinggi atau suspectability rendah, sehingga potensi overfishing rendah. Strategi pengelolaan diekstrak dari tahapan evaluasi dengan skoring dengan melihat hubungan (causalitas) dari nilai dari bobot, atribut dan kualitas data yang diperoleh serta indek kerentanan.

\section{HASIL DAN PEMBAHASAN Hasil}

Perikanan bycatch tuna dari Pelabuhanratu didominasi pada tiga jenis ikan bycatch yaitu ikan baby tuna, ikan cakalang, dan ikan lemadang selain sea turtle (Bertram et al, 2010). Jenis-jenis ikan yang kemudian dikaji terlihat pada Gambar 2 berikut.

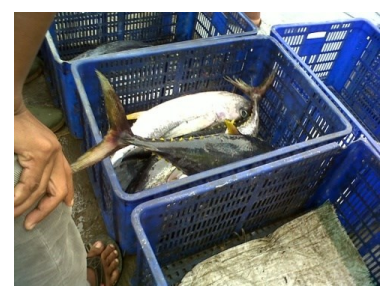

A

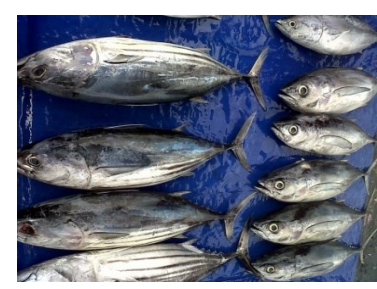

B

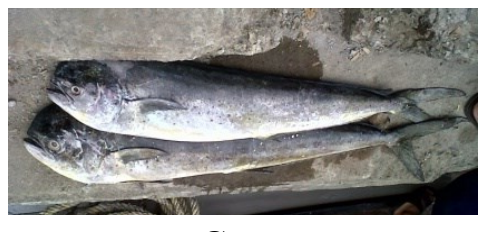

C

Gambar 2. Jenis ikan bycatch tuna Baby tuna (A), Cakalang (B) dan Lemadang (C)

Penentuan nilai produktivitas diantaranya menggunakan parameter ukuran maksimum, koefisien pertumbuhan, pertama kali matang gonad, umur maksimum, fekunditas, kematian alami, rekruitmen, dan tingkat trofik level. Nilai setiap parameter dari ketiga jenis ikan tersebut disajikan pada Tabel 2.

Panjang maksimum ikan baby tuna adalah sekitar $62,42 \mathrm{~cm}$, koefisien pertumbuhan (k) sebesar 0,86 per tahun, umur maksimum yang dapat dicapai 9 tahun. Laju pertumbuhan intrinsik (r) sebesar 1,42 dan fekunditas mencapai lebih dari 200.000-30.310.000 butir. Dalam penelitian ini tidak ditemukan baby tuna yang matang gonad. Ikan tuna memijah satu kali setahun dengan mengeluarkan semua telurnya dalam satu kali musim pemijahan. Tingkat kematian alami 0,68, tingkat rekruitmen sebesar 17,86 dan pertama kali akan memijah pada umur 1,5 tahun. 
Tabel 2 Parameter produktivitas baby tuna, cakalang, dan lemadang

\begin{tabular}{|l|l|l|l|}
\hline Parameter & Baby tuna & Cakalang & Lemadang \\
\hline Pertumbuhan Instrisik (Intrinsic growth) & $1.42 /$ Tahun* & $2.26 /$ Tahun* & $3.86 /$ Tahun* \\
\hline Umur Maksimum (Max age) & 9 Tahun* & 12 Tahun* & 4 Tahun* \\
\hline Ukuran Maksimum (Max size) & 624.23 & 613.73 & 942.9 \\
\hline Laju pertumbuhan/K (Growth coefficient) & 0.86 & 0.93 & 1.2 \\
\hline Kematian alami/M (Natural mortality) & 0.68 & 0.72 & 0.76 \\
\hline Fekunditas (Fecundity) & $200000-30310000$ & $181010-440596$ & $667917-2451044$ \\
\hline Strategy pemijahan (Breeding strategy) & Total Spawner & Parsial Spawner & Parsial Spawner \\
\hline Pola recruitment (Rekruitmet pattern) & $17.86 \%$ & $22.66 \%$ & $18.19 \%$ \\
\hline Umur saat matang gonad (Age at Maturity) & 1.5 Tahun* & 1.3 Tahun* & 0.4 Tahun* \\
\hline Rata-rata tropic level (Mean tropic level) & $4.3^{*}$ & $3.8^{*}$ & $4.4^{*}$ \\
\hline
\end{tabular}

Sumber: Fishbase, 2018

Little tuna dan albacores di Indian Ocean panjang maksimum mencapai $240 \mathrm{~cm}$, koefisien tumbuh 0,3, umur maksimum 6,5 tahun, umur mulai matang gonad 2,4 tahun, dan panjang saat matang gonad $56 \mathrm{~cm}$ (Fredou et al. 2016). Yellowfin tuna tumbuh lebih lambat, umur mencapai 10 tahun dan mulai matang sexual 2,8 tahun dan dan memijah sepanjang tahun (Davies et al. 2015). Fekunditas $T$ albacores lebih tinggi dari little tuna yang fekunditas berkisar 17.814 560.792 butir telur dengan rata-rata 109.807 butir (Ardelia et al. 2016). Panjang maksimum baby tuna yang ditemukan dalam penelitian ini kemungkinan sudah mencapai fase matang gonad.

Ikan cakalang memiliki panjang maksimum sekitar sekitar $61,37 \mathrm{~cm}$, koefisien pertumbuhan (k) nya sebesar 0,96 per tahun. Skipjack di South Atlantic dan Indian Ocean panjang maksimum $110 \mathrm{~cm}$, laju pertumbuhan 0,5 , mulai matang gonad tahun dan umur maksimum 12 tahun, serta panjang saat matang gonad mencapai $50 \mathrm{~cm}$ (Fredou et al. 2016). Umur maksimum adalah 12 tahun, pertumbuhan intrinsik (r) sekitar 2,26. Fekunditas ikan cakalang sekitar 181.010440.596 butir dan memijah satu kali selama musim pemijahan. Reproduksi Skipjack diketahui parsial spawner setelah beberapa waktu tertentu di timur pantai barat Afrika (Andrade et al. 2004). Tingkat kematian adalah 0,72 , dengan persentase rekruitmen diperoleh sebesar 22,66, dan pertama kali memijah pada umur sekitar 1,3 tahun. Skipjack tuna hidup sampai 4-5 tahun, tumbuh cepat, mencapai matang gonad pada umur 1,8 tahun dan memijah sepanjang tahun (Davies et al, 2015). Skipjack dominan tertangkap dengan purse seine $(38 \%)$, gillnet $(36 \%)$, pole and line $17 \%$ dan lainnya 9\% (Davies et al, 2015).

Ikan Lemadang memiliki panjang maksimum sekitar 94,29 cm, koefisien pertumbuhan $(\mathrm{k})$ sebesar 1,2 per tahun. Umur maksimum ikan Lemadang kurang dari 4 tahun. Fredou et al. (2016) menyatakan panjang maksimum $\left(\mathrm{L}_{\max }\right)$ ikan Lemadang (C. Hippurus) $180 \mathrm{~cm}$, dengan laju pertumbuhan 0,72. Umur maksimum mampu dicapai 1,8 tahun dan panjang saat matang gonad $51 \mathrm{~cm}$. Laju pertumbuhan intrinsik (r) sekitar 3,86 dengan jumlah fekunditas antara 667.9132.551.046 butir. Ikan lemadang memijah satu kali dengan persentase kematian alami ikan lemadang sebesar 0,76. Coryphaena hippurus tersebar dari Atlantic, Pacific dan India Ocean (Chang and Mander, 2012). Panjang total tercatat $238 \mathrm{~cm}$ (Lasso and Zapata, 1999), dengan umur maksimum 4 tahun (Schwenke and Buckel, 2008). Dugaan mencapai matang gonad pertama kali pada $50 \%$ yaitu ukuran $45,7-54,5 \mathrm{~cm}$ untuk betina dan 47,6-61,8 cm untuk jantan. Pancing dengan tali nilon dapat meningkatkan catchability and mortality (Afonso et al. 2012). Tingkat rekruitmen sebesar 18,15, dan memijah pertama kali pada umur sekitar 0,4 tahun.

Selain produktivitas, tingkat susceptabilitas juga merupakan factor penentu kerentanan yang juga merupakan kelemahan karena ada interaksi dengan ekosistemya. Parameter susceptabilitas yag dievaluasi ditampilkan pada Tabel 3.

Rogan and Mackey (2007) mencatat bahwa di NE Atlantic kelompok megafauna juga banyak tertangkap selain skipjack, baby tuna dan lemadang. Perikanan tuna yang menggunakan alat tangkap purse seine sebagian besar menangkap kelompok ikan yang schooling spesies skipjack (Katsuwonus pelamis), yellowfin (Thunnus albacares) dan big eye tuna (Davies et al. 2015). Perikanan artisanal dapat menangkap ikan ini karena tidak secepat high migratory lainnya (Belhabib et al. 2016). Kemampuan survival after capture ditentukan tidak hanya karena respon adaptasi tetapi juga karena jenis mata pancing (Huang et al. 2016). Perubahan jenis alat pancing dari modej $\mathrm{J}$ menjadi $\mathrm{O}$ (lingkaran) meningkatkan kemampuan survival bycatch dan menurunkan kematian post release (Asch et al, 2018). Sekitar 20-30\% sword fish hidup hidup saat handling dan kemdian berubah kearah kematian, yang memerlukan adaptasi dari bycatch 
(Canauthers EH, DC Schneider, JD Nielsen, 2009). Peningkatan resiko dapat terjadi karena banyak jenis dan tipe alat yang digunakan dalam area secara bersamaan (Riskas et al. 2016).

Sebagian besar ikan tuna tersebar luas dalam lintang gografis dengan migrasi dan beradaptasi dengan baik (Asch et al. 2018). Migrasi dan perubahan makanan dapat berpengaruh terhadap vulnerability Thunus allalungga (Williams et al. 2015). Tekanan terhadap bycatch tuna juga dapat terjadi karena recreational fishing kemudian kemudian juga turut menurunkan diversity dan jumlah tangkapan seperti Coryphaena hippurus dan Thunus allalungga NW Mediteranean (Lloret et al. 2008). Penurunan bycatcth menjadi dasar bai EBFM (Ecosystem Based Fisheries Approach) untuk mengetahui tingkat resiko terhadap tuna (Hahlbeck et al. 2017). Pembatasan jumlah bycatch untuk migratory species bisa dilakukan dengan pendekatan tingkat kumulative mortalitasmenyangkut batasan potensi biology yang dipindahkan (PBR) karena penangkapan (Riskas et al. 2016).

Tabel 3 Parameter suseptabilitas baby tuna, cakalang, dan lemadang

\begin{tabular}{llll}
\hline Parameter & \multicolumn{1}{c}{ Baby tuna } & \multicolumn{1}{c}{ Cakalang } & \multicolumn{1}{c}{ Lemadang } \\
\hline & Tidak memiliki batasan pe- & Tidak memiliki batasan pe- & Tidak memiliki batasan pe- \\
& nangkapan karena merupakan & nangkapan karena merupakan & nangkapan karena merupakan \\
Management Strategy & hampil samgan dari pe- & hasil sampingan dari pe- & hasil sampingan dari penangka- \\
& nangkapan tuna dan tidak ada & nangkapan tuna dan tidak ada & pan tuna dan tidak ada langkah- \\
& langkah-langkah pertanggung & langkah-langkah pertanggung & langkah pertanggung jawaban \\
& jawaban yang proaktif & jawaban yang proaktif & yang proaktif
\end{tabular}

Tumpang tindih area (Area overlap)

Daerah Sebaran geografis (Concentrasi geografis)

Tumpang tindih vertical (Vertical overlap)

Rasio Mortalitas fishing terhadap alami (F / M)

$>60 \%$ berada pada daerah penangkapan

$100 \%$ tersebar dari seluruah daerah penangkapan

$100 \%$ berada pada kedalaman yang sama

0.952036

Biomass stok pemijahan SSB (spawning stock biomass)

Migrasi musiman (Seasonal migration)

Kelompok Berkumpul (Schooling aggregation)

Efek morphologi (Morfology affecting)

Kemampuan hidup setelah penangkapan (Survival after Capture) Nilai ekonomi ikan (Desirability/Value of the fishery)

Dampak perikanan pada ekosistem (Fishery Impact to essential fish habitat)

\section{$30 \%$}

ikan yang memiliki tingkat migrasinya tinggi sehingga akan menurunkan tingkat overlap terhadap sumberdaya ikan lainnya

ikan yang hidupnya bergerombol sehingga berpengaruh terhadap hasil tangkapan nelayan

alat tangkap pancing merupakan alat tangkap yang ramah lingkungan sehingga tidak berpengaruh terhadap morfologi ikan yang di tangkap

$65 \%$

Harganya berkisar Rp 25000/ $\mathrm{kg}$, bernilai ekonomis tingg.

alat tangkap pancing merupakan alat tangkap yang ramah lingkungan sehingga tidak ada dampak yang buruk terhadap lingkungan atau sumberdaya ikan lainnya
3.482811

$>60 \%$ berada pada daerah penangkapan

$80 \%$ tersebar dari seluruah daerah penangkapan

$80 \%$ berada pada kedalaman yang sama

$30 \%$

ikan yang memiliki tingkat migrasinya tinggi sehingga akan menurunkan tingkat overlap terhadap sumberdaya ikan lainnya

ikan yang hidupnya bergerombol sehingga berpengaruh terhadap hasil tangkapan nelayan

alat tangkap pancing merupakan alat tangkap yang ramah lingkungan sehingga tidak berpengaruh terhadap morfologi ikan yang di tangkap

$60 \%$

Harganya berkisar Rp 18000/ $\mathrm{kg}$, bernilai ekonomis tinggi.

alat tangkap pancing merupakan alat tangkap yang ramah lingkungan sehingga tidak ada dampak yang buruk terhadap lingkungan atau sumberdaya ikan lainnya
$>60 \%$ berada pada daerah penangkapan

$75 \%$ tersebar dari seluruah daerah penangkapan

$70 \%$ berada pada kedalaman yang sama

0.90683

$100 \%$

ikan yang memiliki tingkat migrasinya tinggi sehingga akan menurunkan tingkat overlap terhadap sumberdaya ikan lainnya

ikan yang hidupnya bergerombol sehingga berpengaruh terhadap hasil tangkapan nelayan

alat tangkap pancing merupakan alat tangkap yang ramah lingkungan sehingga tidak berpengaruh terhadap morfologi ikan yang di tangkap

$60 \%$

Harganya berkisar Rp 15000/kg, bernilai ekonomis sedang.

alat tangkap pancing merupakan alat tangkap yang ramah lingkungan sehingga tidak ada dampak yang buruk terhadap lingkungan atau sumberdaya ikan lainnya 


\section{Skor Atribut Produktivitas}

Pendekatan kualitatif dari semua parameter produktivitas dilakukan untuk mendapatkan nilai indek kerentanan. Untuk itu dilakukan penilaian dengan skor pada bobot, atribut dari data yang diperoleh. Hasil penilaian skor yang dari data diatas disajikan pada Tabel 4.

Skor bobot dari ikan baby tuna, cakalang dan lemadang rata-ratanya sebesar 2 yang artinya semua parameter memiliki kepentingan yang sama. Skor atribut ikan baby tuna sebesar $(3,7 \pm 0,71)$, cakalang $(3,7 \pm 0,48)$ dan lemadang $(3,7 \pm 0,48)$. Skor produktivitas yang baik karena nilai skor relative tinggi karena proses handling yang baik saat operasi penangkapan dapat mengurangi laju mortalitas dan kondisi kritis dan kerentanan tuna (Gilman, 2014). Secara umum data produktivitas ikan bycatch tuna tergolong baik.

\section{Skor Atribut Susceptabilitas}

Hasil evaluasi parameter susceptabilitas dari masing-masing bycatch perikanan tuna cukup beragam. Tabel berikut menyajikan skor atribut susceptabilitas ikan baby tuna, cakalang dan lemadang. Dari nilai skor diatas, nilai bobot dari parameter susceptabilitas ikan tuna, cakalang dan lemadang yaitu sebesar 2. Rata-rata skor atribut ikan baby tuna, cakalang dan lemadang sama yaitu $(3,61 \pm 0,51)$. Begitu juga data yang mendukung riset ini tergolong cukup dapat diandalkan. Tuna tropis menunjukan pola diet yang berbeda dalam ruang habitat secara vertical. Perubahan komposisi makanan lebih konsisten pada kondisi migrasi vertical dan horizontal. Perbedaan spasial dalam distribusi vertical menunjukkan bahwa kerentanan $T$ albacores sangat dipengaruhi oleh letak geografis (Williams et al, 2015).

Tabel 3 Skor atribut produktivitas dan suceptabilitas ikan baby tuna, cakalang dan lemadang.

\begin{tabular}{|c|c|c|c|c|c|c|c|c|c|}
\hline \multirow[b]{2}{*}{ Productivity Attributes } & \multicolumn{3}{|c|}{ Baby Tuna } & \multicolumn{3}{|c|}{ Cakalang } & \multicolumn{3}{|c|}{ Lemadang } \\
\hline & $\begin{array}{l}\text { Bobot } \\
(1-4)\end{array}$ & $\begin{array}{l}\text { Skor } \\
\text { Atribut } \\
(1-3)\end{array}$ & $\begin{array}{l}\text { Skor } \\
\text { kualitas } \\
\text { data (1- } \\
5 \text { ) }\end{array}$ & $\begin{array}{l}\text { Weight } \\
(1-4)\end{array}$ & $\begin{array}{l}\text { Skor } \\
\text { Atribut } \\
(1-3)\end{array}$ & $\begin{array}{l}\text { Skor } \\
\text { kualitas } \\
\text { data (1- } \\
5 \text { ) }\end{array}$ & $\begin{array}{l}\text { Weight } \\
(1-4)\end{array}$ & $\begin{array}{c}\text { Skor } \\
\text { Atribut } \\
(1-3)\end{array}$ & $\begin{array}{l}\text { Skor } \\
\text { kualitas } \\
\text { data (1- } \\
5 \text { ) }\end{array}$ \\
\hline $\begin{array}{l}\text { Pertumbuhan Instrisik (Intrinsic } \\
\text { growth) }\end{array}$ & 4 & 3 & 4 & 4 & 3 & 4 & 4 & 3 & 4 \\
\hline Umur Maksimum (Max age) & 3 & 3 & 4 & 3 & 2 & 4 & 3 & 3 & 4 \\
\hline Ukuran Maksimum (Max size) & 3 & 2 & 1 & 3 & 2 & 1 & 3 & 2 & 1 \\
\hline $\begin{array}{l}\text { Laju pertumbuhan/K (Growth } \\
\text { coefficient) }\end{array}$ & 4 & 3 & 1 & 4 & 3 & 1 & 4 & 3 & 1 \\
\hline Kematian alami/M (Natural mortality) & 4 & 3 & 1 & 4 & 3 & 1 & 4 & 3 & 1 \\
\hline Fekunditas (Fecundity) & 4 & 3 & 1 & 4 & 3 & 1 & 4 & 3 & 1 \\
\hline $\begin{array}{l}\text { Strategy pemijahan (Breeding } \\
\text { strategy) }\end{array}$ & 4 & 2 & 1 & 4 & 2 & 1 & 4 & 2 & 1 \\
\hline $\begin{array}{l}\text { Pola rekruitment (Recruitment } \\
\text { pattern) }\end{array}$ & 4 & 2 & 1 & 4 & 2 & 1 & 4 & 2 & 1 \\
\hline $\begin{array}{l}\text { Umur saat matang gonad (Age at } \\
\text { Maturity) }\end{array}$ & 4 & 3 & 4 & 4 & 3 & 4 & 4 & 3 & 4 \\
\hline $\begin{array}{l}\text { Rata-rata tropic level (Mean tropic } \\
\text { level) }\end{array}$ & 3 & 1 & 4 & 3 & 1 & 4 & 3 & 1 & 4 \\
\hline \multirow[t]{2}{*}{ Rataan } & 3,7 & 2.5 & 2.2 & 3,7 & 2.40 & 2.20 & 3,7 & 2.50 & 2.20 \\
\hline & \multicolumn{3}{|c|}{ Baby Tuna } & \multicolumn{3}{|c|}{ Cakalang } & \multicolumn{3}{|c|}{ Lemadang } \\
\hline Atribut Susceptabilitas & $\begin{array}{c}\text { Bobot } \\
(1-4)\end{array}$ & $\begin{array}{c}\text { Atribut } \\
\text { score } \\
(1-3)\end{array}$ & $\begin{array}{c}\text { Skor } \\
\text { quality } \\
\text { data } \\
(1-5) \\
\end{array}$ & $\begin{array}{l}\text { Bobot } \\
(1-4)\end{array}$ & $\begin{array}{c}\text { Atribut } \\
\text { score } \\
(1-3)\end{array}$ & $\begin{array}{c}\text { Skor } \\
\text { quality } \\
\text { data } \\
(1-5) \\
\end{array}$ & $\begin{array}{c}\text { Bobot } \\
(1-4)\end{array}$ & $\begin{array}{l}\text { Atribut } \\
\text { score } \\
(1-3)\end{array}$ & $\begin{array}{l}\text { Skor } \\
\text { quality } \\
\text { data } \\
(1-5)\end{array}$ \\
\hline Manaement Strategi & 4 & 3 & 2 & 4 & 3 & 2 & 4 & 3 & 2 \\
\hline $\begin{array}{l}\text { Tumpang tindih area (Area } \\
\text { overlap) }\end{array}$ & 4 & 3 & 2 & 4 & 3 & 2 & 4 & 3 & 2 \\
\hline $\begin{array}{l}\text { Daerah Sebaran geografis } \\
\text { (Concentrasi geografis) }\end{array}$ & 4 & 1 & 2 & 4 & 1 & 2 & 4 & 1 & 2 \\
\hline $\begin{array}{l}\text { Tumpang tindih vertical } \\
\text { (Vertical overlap) }\end{array}$ & 3 & 3 & 2 & 3 & 3 & 2 & 3 & 3 & 2 \\
\hline $\begin{array}{l}\text { Rasio Mortalitas fishing } \\
\text { terhadap alami (F / M) }\end{array}$ & 4 & 2 & 1 & 4 & 3 & 1 & 4 & 2 & 1 \\
\hline $\begin{array}{l}\text { Kematian penangkapan } \\
\text { (Fishing mortality) }\end{array}$ & 4 & 3 & 1 & 4 & 2 & 1 & 4 & 1 & 1 \\
\hline $\begin{array}{l}\text { Biomass stok pemijahan SSB } \\
\text { (spawning stock biomass) }\end{array}$ & 3 & 1 & 1 & 3 & 1 & 1 & 3 & 1 & 1 \\
\hline $\begin{array}{l}\text { Migrasi musiman (Seasonal } \\
\text { migration) }\end{array}$ & 3 & 3 & 1 & 3 & 3 & 1 & 3 & 3 & 1 \\
\hline $\begin{array}{l}\text { Kelompok Berkumpul } \\
\text { (Schooling aggregation) }\end{array}$ & 3 & 3 & 1 & 3 & 3 & 1 & 3 & 3 & 1 \\
\hline $\begin{array}{l}\text { Efek morphologi (Morfology } \\
\text { affecting) }\end{array}$ & 4 & 2 & 1 & 4 & 2 & 1 & 4 & 2 & 1 \\
\hline $\begin{array}{l}\text { Kemampuan hidup setelah } \\
\text { penangkapan (Survival after } \\
\text { Capture) }\end{array}$ & 3 & 3 & 1 & 3 & 3 & 1 & 3 & 2 & 1 \\
\hline $\begin{array}{l}\text { Nilai ekonomi ikan } \\
\text { (Desirability/Value of the } \\
\text { fishery) }\end{array}$ & 4 & 1 & 1 & 4 & 1 & 1 & 4 & 1 & 1 \\
\hline $\begin{array}{l}\text { Dampak perikanan pada } \\
\text { ekosistem (Fishery Impact to } \\
\text { essential fish habitat) }\end{array}$ & 4 & 3 & 2 & 4 & 3 & 2 & 4 & 3 & 2 \\
\hline
\end{tabular}




\section{PEMBAHASAN}

Tingkat kerentanan ikan bycatch tuna dari kedua atribut diatas yang dilakukan diperoleh nilai kerentanan dari ikan baby tuna adalah 1,41 , ikan cakalang 1.14 dan 1,38 untuk ikan lemadang. Menurut Patrick et al (2009) bahwa nilai kerentanan yang lebih besar dari 1,8 tergolong potensial overfishing. Berdasarkan kriteria tersebut diperoleh nilai kerentanan ketiga jenis ikan (baby tuna, cakalang, dan lemadang) masih kurang dari 1,8, yang berarti belum berpotensi overfishing. Nilai kerentanan tersebut tergolong rendah namun tetap perlu diperhatikan tingkat pemanfaatannya bycatch tuna agar tidak terjadi tangkap lebih atau overfishing. Kondisi ini dapat berbahaya terutama terhadap baby tuna yang perlu dijaga agar menjadi dewasa untuk kemudian baru ditangkap. Hasil perhitungan dengan software PSA NOAA diperoleh nilai sebagai berikut.

Tabel 6 Tingkat Kerentanan Ikan Baby tuna, Cakalang, dan Lemadang

\begin{tabular}{cccccc}
\hline \multirow{2}{*}{ Stok } & \multicolumn{4}{c}{ Productivity } & \multicolumn{2}{c}{ Suceptability } & \\
\cline { 2 - 5 } & $\begin{array}{c}\text { Op } \\
\text { Atrib } \\
\text { ut } \\
\text { Skor }\end{array}$ & $\begin{array}{c}\text { Op } \\
\text { Quali- } \\
\text { ty } \\
\text { Skor }\end{array}$ & $\begin{array}{c}\text { Os } \\
\text { Atrib } \\
\text { ut } \\
\text { Skor }\end{array}$ & $\begin{array}{c}\text { Os } \\
\text { Qual } \\
\text { ity } \\
\text { Skor }\end{array}$ & \\
Baby Tuna & 2,46 & 2,14 & 2,30 & 1,35 & 1,41 \\
ity \\
Cakalang & 2,54 & 2,14 & 2,05 & 1,35 & 1,14 \\
Lemadang & 2,54 & 2,14 & 2,30 & 1,35 & 1,38 \\
\hline
\end{tabular}

Jika dibandingan dari ketiga jenis bycatch tersebut, secara umum proses pengumpulan data yang dilakukan tergolong baik dan data dapat diandalkan. Skor kualitas data sebesar 1,38 menyatakan bahwa data input cukup baik sehingga hasil analisis dapat dijadikan gambaran tentang kondisi kerentanan ikan bycatch tuna di Pelabuhanratu seperti ditampilkan pada Gambar 2.

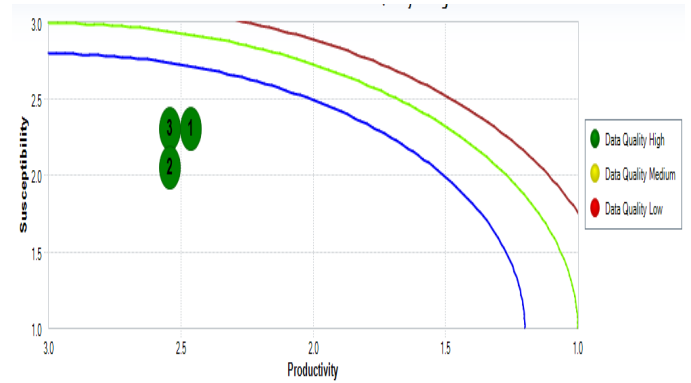

Gambar 3 Vulnerability ikan baby tuna (1) cakalang (2), dan lemadang (3).

Jenis ikan cakalang dan lemadang nilai produktivitasnya lebih tinggi dibandingkan dengan nilai susceptabilitasnya, sehingga belum beresiko terjadi overfishing. Namun untuk ikan baby tuna nilai susceptabilitasnya lebih tinggi jika dibanding dengan produktivitasnya, sehingga ha- rus berhati-hati agar tidak terjadi overfishing. Meningkatnya kerentanan baby tuna tidak mempengaruhi proses recruitment baby tuna, tapi mempengaruhi kemampuan pulih atau resiliensinya tuna dewasa. Jika kemampuan resilience tuna dewasa rendah secara otomatis akan mengarah pada kondisi rentan. Untuk mengantisipasi terjadinya penurunan kualitas tuna dewasa maka dapat dilakukan pengendalian penangkapan baby tuna.

Peningkatan vulnerability skipjack dipengaruhi musiman dan beberapa factor lingkungan seperti kedalaman dan termoklin (Andrade et al, 2004). Jenis yellowfin, skipjack, dan big eye tuna berbeda level susceptabilitasnya, overfishing, variasi laju tumbuh, umur pada saat matang gonad, dan daerah pemijahan (Davies et al, 2015). Fredou et al (2017) menemukan bahwa produktivitas Thunus albacores 2,63, Coryphaena hippurus 2,471, Katsuwonus pelamis 2,471 . Tingkat susceptabilitas Thunus albacores 2,63, Coryphaena 2,09 dam Katsuwonus pelamis 2,143 . Nilai vulnerability score dari Thunus albacores 2,28, Coryphaena hippurus 1,213 dan Katsuwonus pelamis 1,26.

Dalam praktek pengelolaan perikanan yang bertanggungjawab maka resiko kerentanan harus diturunkan. Maka untuk itu kita harus melakukan evaluasi (cascading) dari semua atribut produktivitas dan suceptabilitas. Dari kajian diatas, terlihat parameter yang harus dipantau adalah pertumbuhan intrinsic, pemantauan umur dan ukuran tangkap, dan tropic level. Penting untuk mengendalikan eksploitasi dan menjaga rantai makanan. Pada atribur suceptability strategi manajemen harus diatur lebih baik, tumpeng tindih daerah penangkapan yang terus terjadi harus diatur selain itu juga kondisi ekosistem.

Dalam tata kelola perikanan tuna, tataa kelola alat tangkap, purse seine dan longline merupakan alat utama yang juga menangkap baby tuna, sea turtle dan shark (Gilman, 2011). Hal ini sebagai upaya mendorong pengelolaan perikanan berbasis ekosistem, bycatch tidak boleh lebih dari 8\% (Kirby et al, 2014). Karena hal itu mitigasi bycatch selain mengurangi bycatch, juga perlu pengaturan metode penangkapandan pembatasan daerah penangkapan (Gillman, 2011). Mengurangi fishing mortality bycatch yang telah lebih dari 30\% harus denga mengurangi fishing effort dan FAD (Kirby et al, 2014).

Selain tata kelola alat tangkap, juga diperlukan upaya pemantauan life history tuna. Life history juga digunaka untuk evaluasi trade off antara konservasi dan konservasi species (Juan Jorda et al, 2013, Le Quens and Jenning, 2011 and Fredou, 2012). Pemahaman tentang life history pada ikan target dan bycatch juga jadi pedoman dalam pengelolaan berbasis ekosistem dan sebagai pertimbangan bagi informasi kerentanan- 
kerentanan terhadap beban eksploitasi dan susceptibility terhadap penangkapan (Zhou et al, 2012 and Gilman 2014). Dalam hal susceptibility species bycatch, masih terbatas data dari resiko kepunahan. Kajian life history dari species dan stok membantu menduga efek dari climate change (Cheung et al, 2009), mengetahui kerentanan dan kolaps (Cortes et al, 2009; Patrick et al 2010) dan kepunahan spesies (Olden et al 2008). Selain longline, tradisional tuna traps (Tonnare) juga menangkap banyak bycatch terutama Sardinia (Storai et al, 2011).

Ikan yang tertangkap kemudian direlease menghasilkan dampak fisik yang dapat menurunkan pertumbuhan (Wilson et al, 2014) dan tolerasi resiko dari mortalitas post capture. Komposisi asam lemak memperlihatkan ada interaksi interpsesifik dalam jenis BEY, YFT dan Skipjack (Sardene et al 2016). Taiwan observer mencatat fishing mortality dengan longline tidak lebih dari 0,55/thn (Sun et al, 2002)

Penangkapan mahi-mahi dengan jenis pancing $\mathrm{J}$ dan $\mathrm{O}$ tidak menunjukkan perbedaan yang nyata (Ward et al, 2009). Bycacth juga digunakan untuk mengkaji informasi stok tuna, mitigasi dan menjamin hidup ikan kecil (Huang, 2010). Penangkapan yang tidak menimbulkan resiko adalah pada reference point yaitu laju tangkap antara 36-49\%, spawning biomass 90$98 \%$, spawning motality pada level $3-5 \%$ dalam kondisi MSY (Pillig et al, 2016). Lebih 50\% dari Albacores dan 54\% dari Skippjack merupakan bycatch yang tertangkap dengan longline (Williams et al, 2015) yang berarti dapat beresiko tinggi.

\section{KESIMPULAN}

Kerentanan perikanan bycatch tuna dipelabuhanratu tergolong rendah dan stok masih berpotensi berkelanjutan. Namun demikian dalam tata kelola perikanan yang baik, upaya mitigasi harus tetap dilakukan agar tidak mengarah pada kondisi rentan sedang. Untuk itu tata kelola alat tangkap perlu dilakukan termasuk dalam hal overlapping alat pada daerah penangkapan dan lapisan perairan. Kondisi ini penting untuk menjaga tropic level agar keseimbangan selalu terjaga

\section{UCAPAN TERIMA KASIH}

Pada kesempatan ini penulis mengucapkan terima kasih kepada WWF-Indonesia yang telah memberikan dukungan dalam pelaksanaan pengumpulan data bagi penyelesaian penelitian ini dan diperkenankannya untuk dipublikasikan dalam jurnal ilmiah. Selain itu juga kepada seluruh tm yang terlibat dalam proses pengumpulan datanya dilapangan.
DAFTAR PUSTAKA

Ardelia V, Yonvitner, M Boer. 2016. BIOLOGI REPRODUKSI IKAN TONGKOL Euthynnus affinis DI PERAIRAN SELAT SUNDA. Jurnal Ilmu dan Teknologi Kelautan Tropis, Vol. 8, No. 2, Hlm. 689-700.

Asch RG, WWL Cheung, G Reygondeau. 2018. Future marine Ecosystem Driver, Bioiversity and Fisheries maximum Catch Potential in Pacific Island Country and Toritories Under Climate Change. Marine Policy 88 (2018). 285-294. Elsevier. http:// dx.doi.org/10.1016/j.marpol.2015.12.016

Afonso AS, R Santiago, H Hazin, FHV Hazin. 2012. Shark by catch and Mortality and Hooks Bite-offs in Pelagic Longlines. Interaction Between Hook Type and Leader Material. Fisheries Research 131-133 (2012) 914. Elsevier http://dx.doi.org/10.1016/ j.fishres.2012.07.001

Andrade HA, JAT Santos. 2004. Seasonal trend in the Recruit at of Skipjack tuna (katsuwonus pelamis) to the fishing ground in the south west Atlantic. Fisheries Research 66 (2004) 185-194. Elsevier. doi:10.1016/S0165-7836(03)00199-1

Bertram PK, JK Kaneko, KK-Nakamura. 2010. Sea Turtle bycatch to Fish Cacth Rasio for Differentiating Hawai Longline Caught Seafood Product. Marine Policy 34 (2010) 145 -149. Elsevier. doi:10.1016/ j.marpol.2009.05.006

Belhabib D, VWY Lam, W.W.L.Cheung. 2016. Overview of West Afrika Fisheries Indicator Climate Change. Impact, Vulnerability of Adaptation Respon of Artisanal and Industrial Sector. Marine Policy 71(2016) 1528. Elsevier. http://dx.doi.org/10.1016/ j.marpol.2015.12.016

Chang SK, MN Maunder. 2012. Aging Material Matters in The Estimation of Van Bartallanfy Growth Parameter for Dolphinfish (Coryphaena hippurus). Fisheries Research 119-120 (2012) 147-153. Elsevier . doi:10.1016/j.fishres.2011.01.018

Carruthers EH, DC Schneider, JD Neilson. 2009. Estimating the odds of Survival and Ientifying Mitigation Opportunities for Common bycatch in Pelagic Longline Fisheries. Biological Conservation. 142. (2009) 26102630. Elsevier. doi:10.1016/ j.biocon.2009.06.010

Davies TK, CC Mees, EJ Milner, Gulland. 2015. Second guesing Uncertainty: Scenario Planning for management of The Indian Ocean Tuna Purse Seine Fisheries. Marine Policy 62 (2015) 169-177. Elsevier. http:// dx.doi.org/10.1016/j.marpol.2015.09.019 
Davies TK, CC Mees, EJ Milner, Gulland. 2015. Second guesing Uncertainty: Scenario Planning for management of The Indian Ocean Tuna Purse Seine Fisheries. Marine Policy 62 (2015) 169-177. Elsevier. http:// dx.doi.org/10.1016/j.marpol.2015.09.019

Fredou FL, L Kell, T Fredou, D Gaertner, M Potier, P Bach, P Travassos, F Hazin, F Menard. 2017. Vulnerability of Teleost Caught by the Pelagic Tuna Longline Fleet in South Atlantic and Western Indian Oceans. DeepSea Research II. 140 (2017) 230-241. http://dx.doi.org/10.1016/ j.fishres.2015.09.018

Fredou FL, L Kell, T Fredou, D Gaertner, M Potier, P Bach, P Travassos, F Hazin, F Menard. 2016. Life History Traits and Fishery Pattern of Teleost Caught by the Tuna Longline in The South Altantic and Indian Ocean. Fisheries Research 179 (2016) 308-310. http://dx.doi.org/10.1016/ j.fishres.2016.03.013.

Gilam EL. 2011. Bycatch Governance and Best Practise Mitigation Technology in Global Tuna. Marine Policy 35 (2011) 590-609. Elsevier. doi:10.1016/j.marpol.2011.01.021

Gilman E, M Owen, T Kraft. 2014. Ecological Risk Assesement of The Marshall Island Longline Tuna Fishery. Marine Policy 44 (14) 239-255. Elsevier. http:// dx.doi.org/10.1016/j.marpol.2013.08.029

Huang HW, 2011. Bycatch of high sea longline fisheries and measures taken by Taiwan: Action and Challangge. Marine Policy 35 (2011) 712-720. Elsevier. doi:10.1016/ j.marpol.2011.01.021

Hahlbeck N, KL Scales, H Dewan, SM Maxwell, SJ Bograd, EL Hazen. 2017. Oceanographic Determinant of Ocean Sunfish (Molamola) and Bluefin tuna (Thunnus orientalis) bycatch Pattern in The California Large Mesh Size Drift Gilnet Fishery. Fisheries Research 191 (2017) 154-163. http:// dx.doi.org/10.1016/j.fishres.2017.03.011.

Huang HW, KM Liu. 2010. Bycatch and Discard by Taiwanese Large Scale Tuna Longline in the Indian Ocean. Fisheries Research. 106 (2010) 261-270. Elsevier. doi:10.1016/ j.fishres.2010.08.005

Huang HW, Y Swimer, K Bigelow, A Guiterez, DG Foster. 2016. Infulence of Hand Type on Catch of Comercial and bycatch Species in an Atlantic tuna fisheries. Marine Policy 65 (2016) 68-75. Eslevier. http:// dx.doi.org/10.1016/j.marpol.2015.12.016

Lloret J, N Zaragoza, D Cabalero, V Riera. 2008. Biological and Socioeconomic Implication of Recreational Boat Fishing for The Management of Fishing Resources in The Marine Reserve of Cap de Creus (NW Mediter- anian). Fisheries Research 91 (2008) 252$259 . \quad \mathrm{http}: / / \mathrm{dx}$.doi.org/10.1016/ j.dsr2.2007.12.002

Lasso J, Zapata L. 1999. Fisheries and Biology of Coryphaena hippurus (Pisces:Corypahenidae) in The Pacific Coast of Colombia and Panama. Sci.Mar. 63 (1999) 387-399. Elsevier

Kirby DS, C Visserm Q Hanich. 2014. Assesement of Eco-Labelling Schemes for Pacific Tuna Fisheries. Marine Policy 43 (2014) 132-142. Elsevier. http:// dx.doi.org/10.1016/j.marpol.2013.05.004

Sunoko R and HW Huang. 2014. Indonesia tuna Fisheries Development and Future Strategy. Marine Policy 43 (2014) 174-183. Elsevier. $\quad \mathrm{http}: / / \mathrm{dx}$.doi.org/10.1016/ j.marpol.2013.05.011

Olson RJ, MH Roman-Verdesoto, GL MaciasPita. 2006. Bycatch of Jumbo Squid Dosidicus gigas in the Tuna Purse Seine fishery of the eastern Pacific Ocean and Predatory Behavior During Capture. Fisheries Research 79 (200) 48-55. Elsevier. doi:10.1016/ j.fishres.2006.02.012

Pilling GM, AM Berger, C Reid, SJ Harley, J Hampton. 2016. Candidate Biological and Economic target Reference Point for the South Pacific Albacore. Longline Fisheries. Fisheries Research 174 (2016) 167-178 Elsevier. $\quad \mathrm{http}: / / \mathrm{dx}$.doi.org/10.1016/ j.fishres.2015.09.018

Puspita R, M Boer, Yonvitner. 2017. Tingkat Kerentanan Ikan Tembang (Sardinella fimbriata, Valenciennes 1847 ) dari Kegiatan Penangkapan dan Potensi Keberlanjutandi Perairan Selat Sunda. Jurnal Pengelolaan Perikanan Tropis. Vol 1 No 1 Hal 17-23. DOI: $\quad$ http://dx.doi.org/10.29244/ jppt,1,01,17-23

Patrick WS; P Spencer; O Ormseth; J Cope; J.Field; D Kobayasi; T Gedamke; E Cortes; K Bigelow; W Overholtz; J Link; P Lawson. 2009. Use of Productivity and Suceptability Indices to Determine Stock Vulnerability, with Example Application ti six US Fisheries. UA Dept of Commerce, NOAA.

Pasparakis C., EM Mager., JD Stieglitz, D Benneti, M Grosell. 2016. Effect of Deepwater Horizon Crude Oil Exposure, Temperature, and Developmental Stage on Oxygen Consumption of Embrionic and Larval MahiMahi (Corphaena hippurus). Aquatic Toxicology 181. (2016). 113-123. Elsevier. http://dx.doi.org/10.1016/ j.aquatox.2016.10.022 
Rogan E, M Mackey. 2007. Megafauna bycatch in driftnet for Albacore tuna. (Thunus allalungga) in the NE Atlantic. Fisheries Research 86 (2007) 6-14. Elsevier . doi:10.1016/j.fishres.2007.02.013

Riskas KA, MMPB Fuetes, M Haman. 2016. Justifyig the need for Collaborative Management of Fisheries bycatch. A Lesson from Marine Turtle in Australia. Biologycal Conservation 196 (2016) 40-47. Elsevier. http:// dx.doi.org/10.1016/j.biocon.2016.02.001

Sardenne F, N Bodin, E Chassot, A Amiel, E Fouche, M Degroote, S Holanda, H Pethybridge, B Lebreton, G Guillou, F Menard. 2016. Tropic Niche of Sympatric Tropical tuna in Western Indan Ocean Infered by Stable Isotop and Neutral Fatty Acid. Pross in Oceanography 146 (2016) 75-88/ Els. doi:10.1016/j.fishres.2006.02.012

Sun CI, NM Ehrhardt, CE Porch, SZ Yeh. 2002. Analyses of Yield and Spawning Stock Biomass Per recruit for the South Atlantic albacore. Fisheries Research 56 (2002) 193-204. Elsevier

Storai T, L Zinzula, S Repetto, M Zuffa, A Morgan. J Mandelman. 2011. Bycatch of large elasmobranchia in the Tradisional tuna traps (Tonnare) of Sardinia from 1990-2009. Elsevier. doi:10.1016/j.fishres.2011.01.018

Schwenke KL, JA Buckel. 2008. Age and Growth of Coryphaena hippurus Caught of The Coast of North Carolina. Fish Bull. Elsevier. 106. 83-92.

Suryaman E, Mennofatria Boer, Luky Adrianto, Lilis Sadiyah. 2017. Analisis Produktivitas dan Suceptabilitas Pada Tuna Neritik di Pelabuhanratu. Jurnal Penelitian Perikanan Indonesia. Vol 23 No 1 Halaman 19-28. DOI: $\quad$ http://dx.doi.org/10.15578/ jppi.23.1.2017.19-28

Ward P, S Epe, D Kreutz, E Lawrence, C Robin, A Sands. 2009. The Effect of Circle hooks $\mathrm{J}$ on bycatch and target catches in Austalia Pelagic Longline fisheries. Fisheries Research 97 (2009) 253-262. Elsevier. doi:10.1016/j.fishres.2009.02.009

Williams AJ, V Allain, SJ Nicol, KJ Evans, SD Hoyle, C Dupoux, E Vourey, J Dubosc. 2015. Vertikal Behavior and Diet of Albacores Tuna (Thunnus allalunga) Vary with Latitude in The South Pacific Ocean. Deep Sea Research 11-113 (2015) 154-169. Elsevier.

http://dx.doi.org/10.1016/ j.dsr2.2014.03.010

Wilson SM, GD Raby; NJ Burnett; SG Hinch; SJ Cooke. 2014. Looking Beyond the Mortality of bycatch. Sub Lethal effect of Incidental Capture on Main Animal. Biology
Conservation. 171 (2014) 61-71. Els. http:// dx.doi.org/10.1016/j.biocon.2014.01.020

Yonvitner, Isdradjad Setyobudiandi, Achmad Fahrudin, Ridwan Affandi, Etty Riani dan Nurfitri Triramdani. 2017. Review Indikator Dari Indek PSA NOAA Untuk Ikan Pelagis Kecil (Tembang: Sardinella sp.; Famili Clupeidae) dan Ikan Demersal (Kuris: Nemipterus sp.; Famili Nemipteridae). Jurnal Teknologi dan Manajemen Perikanan Laut. Vol 8 No 8 hal 123-135. DOI: http://dx.doi.org/10.29244/jmf.8.2.123 $-135$

Yonvitner, Isdradjad Setyobudiandi, Apriansyah, Deni Rahmat Hidayat. 2017. Tropical Eel: Vulnerability Approach untuk Pengelolaan Berkelanjutan. Jurnal Pengelolaan Perikanan Tropis. Vol 1 No 1 hal 41-50. DOI: http://dx.doi.org/10.29244/ 